\title{
Da instrução à educação: aportes para a compreensão do audiovisual como tecnologia educacional
} From instruction to education: contributions to the understanding of audiovisual as an educational technology

\section{De la instrucción a la educación: contribuciones a la comprensión del audiovisual como tecnología educativa}

Vanessa Matos dos Santos ${ }^{1}$

DOI: http://dx.doi.org/10.20435/serie-estudos.v23i47.1065

\begin{abstract}
Resumo: Este artigo oferece uma revisão conceitual sobre a utilização dos audiovisuais em processos educativos. Para tanto, apresenta-se, inicialmente, um breve histórico que focaliza o debate conceitual e aprofundado entre tecnologia instrucional e tecnologia educacional. A cronologia traçada fornece respaldo para a abordagem do audiovisual no contexto de desenvolvimento das mídias massivas oscilando seu papel, ora como tecnologia instrucional, ora como tecnologia educacional. Finalmente, apresenta-se e problematiza-se o papel do audiovisual na sociedade contemporânea, permeada pelas tecnologias digitais. O objetivo maior deste manuscrito é investigar as bases que sustentam o uso educacional do audiovisual e oferecer arcabouço histórico e conceitual que viabilize sua permanência e desenvolvimento em outros suportes que permeiam o mundo contemporâneo (como smartphones e tablets) e não apenas em aparelhos televisivos.
\end{abstract}

Palavras-chave: tecnologia educacional; audiovisuais; instrução; mídia.

\begin{abstract}
This article provides a conceptual review of the use of audiovisual in educational processes. It presents, initially, a brief history that focuses on the debate between instructional technology and educational technology. The chronology drawn provides support for the audiovisual approach in the context of development of mass media. Finally, it presents and discusses the role of audiovisual media in contemporary society permeated by digital technologies. The main objective of this manuscript is to investigate the foundations that support the educational use of audiovisual and offer historical and conceptual contributions that enables its permanence and development in other media (such as smartphones and tablets) and not only in televisions.
\end{abstract}

Keywords: educational technology; audiovisuals; instruction; media.

\footnotetext{
${ }^{1}$ Universidade Federal de Uberlândia (UFU), Uberlândia, Minas Gerais, Brasil.
} 
Resumen: Este artículo ofrece una revisión conceptual de la utilización de audiovisuales en los procesos educativos. Presenta, inicialmente, una breve cronología que se centra en el debate entre la tecnología instruccional y la tecnología educativa. La cronología dibujada ofrece apoyo al enfoque audiovisual en el contexto del desarrollo de los medios de comunicación. Por último, se presenta y discute el papel de los medios audiovisuales en la sociedad contemporánea permeada por las tecnologías digitales. El principal objetivo de este manuscrito es investigar las fundaciones que apoyan el uso educativo de audiovisuales y ofrecer marco histórico y conceptual que permita su permanencia y desarrollo en otros medios de comunicación (como smartphones y tabletas) y no sólo en los televisores.

Palabras clave: tecnología educativa; audiovisuales; instrucción; medios.

\section{INTRODUÇÃO}

Para compreender este debate, é importante localizar historicamente os termos em questão e aclarar conceitos. Em realidade, a historiografia do desenvolvimento dessas tecnologias reflete, muito mais que um conceito, um modelo de sociedade (e, consequentemente, de Educação) de uma época. Tendo essa assunção como ponto de partida, é possível perceber as diversas nuances que essas tecnologias foram adquirindo ao longo dos anos. Entende-se que é, antes de tudo, essencial compreender o debate existente entre os termos tecnologia educacional e tecnologia instrucional. Cabe aqui, no entanto, um esclarecimento inicial: não importam os artefatos técnicos em si, mas, assim como apregoa Selwyn (2011, p. 3), o foco está "nas práticas e atividades que os rodeiam, nos significados que as pessoas thes atribuem e nas relações sociais e estruturas às quais as tecnologias se ligam". As tecnologias não são neutras e, embora não seja algo muito destacado na literatura sobre a temática, elas resistem em função dos usos e apropriações feitas pelas pessoas em seus cotidianos. Isso significa que, por mais que uma tecnologia seja pensada no interior de um laboratório, é nas ruas que seu significado será realmente conhecido (JOHNSON, 2001; FEENBERG, 2001). Nesse aspecto, não se busca discutir o desenvolvimento tecnológico, e sim o sentido desse desenvolvimento (fenômeno que não se pode frear) rumo à construção de algo coletivo (KLINGE, 2000). Superando a dicotomia arcaica entre tecnófobos e tecnófilos, desenvolver esse debate torna-se, portanto, uma responsabilidade que precisa ser compartilhada por todos, especialmente entre os educadores. Embora exista a compreensão de que o uso das tecnologias (quer sejam consideradas instrucionais ou educacionais) enseja movimentos políticos e ideológicos, é preciso avançar no sentido de responder à seguinte questão: o 
que se pode fazer diante do cenário em que vivemos? Ao invés de negar o uso, propõe-se que nos apropriemos das tecnologias.

Uma análise histórica breve permite perceber que o uso da tecnologia com objetivos educacionais não é algo recente. Muitos sistemas foram criados com a concepção de uma educação programada e, portanto, instrutiva. Isso não significa, no entanto, que dispensassem o papel do professor ou que fossem feitas de uma forma mecânica, desprovidas de reflexão. O aspecto programado e instrucional era o referencial da época e, por isso, o termo se generalizou. Ademais, mesmo os profissionais que trabalhavam com isso precisaram repensar seus papéis, de onde surgiram: o design instrucional, desenvolvedores instrucionais etc.

O termo "educacional" passou a ser reivindicado anos à frente e invocava a necessidade de que o foco de todo e qualquer processo que se utilizasse de tecnologias para a educação, deveria ser, em essência, o processo educativo, a ação de ensinar e aprender e não a instrução. Gentry (1995) localiza a diferença entre os termos especificando que a tecnologia instrucional está orientada para aplicações estratégicas oriundas das ciências físicas e comportamentais para solucionar problemas instrucionais. Em contrapartida, a tecnologia educacional faz referência à combinação de tecnologias instrucionais, de aprendizagem, desenvolvimento, gerenciamento e outras tecnologias empregadas para resolver problemas educacionais. Caberia, no entanto, o questionamento sobre a diferença entre o que seriam problemas instrucionais e problemas educacionais.

Ademais, não se trata apenas de uma discussão de cunho pedagógico. Também os profissionais que trabalham na área, entre professores, educadores, pedagogos, comunicadores, designer, programadores etc., seguem em discussão sobre a denominação de suas funções ou, no mínimo, campo de atuação. As duas vertentes possuem bons argumentos, bem como publicações que fundamentam extensamente seus motivos e objetivos, a saber: Seels e Richey (1994) com a publicação de Instructional Technology: the definition of the field, buscavam justamente trazer argumentos sobre a adoçao do termo instrucional. Em 2008, no entanto, Januszewski e Molenda (2008) lançaram Educational technology: a definition with commentary, defendendo argumentos para o uso do termo educacional.

É importante destacar que as duas publicações receberam o apoio da Association for Educational Communications and Technology (AECT), ou seja, em distintos momentos, a entidade de maior representatividade sobre o tema, adotou 
nomenclaturas diferentes. Em seu início, entre 1972 e 1977, a AECT adotava o termo tecnologia educacional. Em 1994, passou a usar o termo tecnologia instrucional e, novamente, em 2008, passou a adotar tecnologia educacional. Segue o excerto em que Januszewski e Molenda (2008, p. ix) justificam a mudança terminológica:

Este livro apresenta a definição do campo de estudo e prática da "tecnologia educacional" ou "tecnologia instrucional". Mesmo reconhecendo que os termos educacional e instrucional têm conotações diferentes, os autores pretendem que essa definição possa abranger a ambos. Pode-se argumentar que um termo é mais amplo e inclusivo em alguns casos, mas o Comitê atual de Definição e Terminologia escolhe concentrar-se sobre sentido segundo o qual a educação representa um termo mais amplo. (tradução nossa) ${ }^{2}$

Não tardou até que as reações ocorressem e reivindicassem o termo instrucional. Posteriormente, Lowenthal e Wilson (2010) demonstraram que existe uma maior abrangência com o uso do termo instrucional. No Brasil, no entanto, a terminologia "tecnologia educacional" passou a ter maior abrangência e a fazer parte do cotidiano de educadores e pedagogos, principalmente a partir da criação da Associação Brasileira de Tecnologia Educacional (ABT).

\section{BREVE CRONOLOGIA}

Esforçando-se por traçar uma cronologia dessas tecnologias que, para ela, se traduzem por tecnologias de desenvolvimento, Schrock (1995) revela que tal atividade está relacionada a um sistema de autocorreção que visa aplicar os princípios derivados cientificamente para o planejamento, design, criação, implementação e avaliação de uma instrução eficaz e eficiente ${ }^{3}$. A própria autora pontua a ausência de uma ligação mais estreita que implique também os estudos de mídia, já que muitas transformações que ocorreram na tecnologia instrucional são oriundas do

\footnotetext{
2 Tradução livre do original This book presents a definition of the field of study and practice as "educational technology" or "instructional technology." While recognizing that educational and instructional have different connotations, the authors intend that this definition encompass both terms. It could be argued that either term is broader and more inclusive in some sense, but the current definition and Terminology Committee chooses to focus on the sense in which education is the broader term. (p. ix)

3 Tradução livre do original: "a self-correcting, systems approach that seeks to apply scientifically derived principles to the planning, design, creation, implementation, and evaluation of effective and efficient instruction" (SCHROCK, 1995).
} 
desenvolvimento dos meios de comunicação. Retomando a questão cronológica, Schrock (1995) divide o desenvolvimento da tecnologia instrucional em décadas, tomando por base o início do século XX como o nascimento do conhecimento empírico como base para os estudos em Educação. A década de 1920 foi marcada pelo princípio de que o cérebro, assim como qualquer músculo, precisava ser constantemente exercitado para que se desenvolvesse. Embora já tivessem sido pensados antes, os planos de instrução começam a ganhar força nessa época. No fundo, contida nesses planos, estava a ideia (ainda embrionária) de que os objetivos deveriam guiar o aprendizado. Os planos buscavam permitir que cada aluno avançasse seus objetivos no seu devido tempo e, nesse sentido, os materiais habilitavam o aluno para que progredisse com uma interferência mínima do professor. Data de 1923 a criação do Departamento de Instrução Visual (DVI), pela NationalEducationAssociation (NEA) nos Estados Unidos, numa clara demonstração de aposta no poder da mídia para fins instrucionais. Ainda assim, tratava-se de uma aposta de forma cautelosa, pois o novo departamento não tinha equipe específica, fixa e tampouco desenvolvia pesquisas ou publicações. Seus primeiros sete anos de existência foram praticamente fechados em projetos sazonais, sem continuidade. Os estudos existiam, mas eram esparsos (KERBAUY; SANTOS, 2011a).

Esses estudos, no entanto, foram freados pela crise de 1929. A década de 1930 foi marcada também pela ascensão do movimento progressista na Educação, o que tornava a pesquisa com aprendizagem instrucional praticamente inviável. O movimento progressista apregoava a liberdade de pensamento, fora do controle praticado pelo princípio da aprendizagem instrucional. Entretanto data desse mesmo período o estudo de Ralph W. Tyler, que propôs, em 1933, o estudo em oito anos ou, do original, "Eight Year Study". Essa proposta curricular era uma alternativa para as pressões do período pós-guerra para uma revisão curricular que privilegiasse também a imensa quantidade de alunos que estava fora das escolas (KERBAUY; SANTOS, 2011b). A pesquisa conduzida por Tyler teve o objetivo de verificar se os alunos que estavam participando dessa proposta curricular alternativa para o ensino médio, teriam condições de dar prosseguimento aos seus estudos em níveis posteriores (universidades e colleges). Trinta escolas secundárias (entre públicas e privadas) participaram do estudo. Reiser (1987) destacou que o estudo de Tyler demonstrou dois pontos importantes para o desenvolvimento da tecnologia instrucional: o primeiro deles é o fato de que os objetivos se tornam 
mais claros se levarem em consideração o comportamento do aluno; por sua vez, o segundo ponto era expresso pela necessidade de garantir que o currículo alternativo estivesse sendo executado conforme planejado. A junção dos dois pontos é que permitiria revisar e melhorar o currículo alternativo.

A década de 1940 foi iniciada com um enorme contingente militar que necessitava de instrução rápida por conta da Segunda Grande Guerra. Não apenas instrução, mas necessitava, sobretudo, treinamento para que estivessem preparados para dar respostas rápidas em situações-limite (SAETTLER, 1968). Por conta dessa emergência, o governo apoiou e investiu maciçamente na criação, em janeiro de 1941, de um departamento, voltada para a produção de materiais audiovisuais direcionados ao atendimento a essa demanda. A Divisão de Audiovisuais para Treinamento de Guerra (tradução livre do original: Division of Visual Aids for War Training), com o apoio do Departamento de Educação dos Estados Unidos, chegou a produzir 457 filmes, 432 filmes mudos e 457 manuais instrucionais desde o período em que foi criada até junho de 1945 (SAETTLER, 1968).

Em 1945, a National Education Association (NEA) inaugura uma nova divisão interna, que foi chamada de Division of Audio-Visual Instructional Services, que tinha como objetivo dar suporte aos vários projetos da associação. A direção da nova Divisão foi compartilhada com o então DVI, criado em 1923. Em 1960, o nome da divisão foi alterado e passou a ser escrito sem hífen e passou a ser chamado de Departamento de Instrução Audiovisual (do original: Departament of Audio Visual Instruction).

Esse período foi marcado pelos estudos e pesquisas envolvendo os materiais audiovisuais para fins educacionais. Mais que apenas o desenvolvimento da tecnologia educacional, esse período também marcou a entrada e utilização massiva das mídias em projetos envolvendo tecnologias e educação. O estudo da tecnologia educacional como disciplina e campo de estudo pode ser localizado a partir dessa década, nos Estados Unidos. Seis anos após as primeiras experiências com militares durante a Segunda Guerra Mundial, a Universidade de Indiana passou a oferecer o estudo do tema como matéria no currículo do curso de Educação Audiovisual. Sobre essa questão, Pons (2001, p. 51) pondera que a "utilização dos meios audiovisuais com uma finalidade formativa constitui o primeiro campo específico da tecnologia educativa". Embora a tecnologia educacional não seja, necessariamente, sinônimo de uso de mídia audiovisual, a tônica inicial dos es- 
tudos foi conduzida para essa direção porque "o estudo das aplicações de meios e materiais ao ensino será uma linha constante de trabalho" (PONS, 2001, p. 51); falar de tecnologia educacional pressupõe, de antemão, o uso de recursos de comunicação, notadamente os audiovisuais. As pesquisas e a formulação da teoria do condicionamento operante de B. F. Skinner (2003) inauguraram, nas décadas de 1950 e 1960, a concepção de instrução programada. Para ele, a aprendizagem humana poderia ser potencializada por meio de reforços em intervalos de tempos específicos. Esse passo representou um deslocamento dos estudos que, até então, focalizavam o comportamento do professor para uma proposta que centralizava o comportamento do aluno. Em que pesem todas as críticas recebidas por Skinner, Schrock (1995) destaca que a instrução programada contribui para inserir no cenário das transformações a ideia de que esses métodos de instrução poderiam ser expandidos por meio do uso das mídias, que não apenas o tradicional material impresso. Essa expansão abriria caminho para os sistemas instrucionais propriamente ditos e que poderiam ser distribuídos em maior escala.

Mais investimentos para as pesquisas e um incremento da produção científica envolvendo a tecnologia foram verificados nas décadas seguintes. Novas pesquisas também começavam a aparecer no cenário mundial, como as discussões sobre os novos sistemas instrucionais conduzidas por Glaser (1962 apud SCHROCK, 1995), que já detalhava o que seriam os sistemas de instrucionais e explicava seu funcionamento. De acordo com Schrock (1995), Glaser já denunciava a enorme distância existente entre os estudos de psicologia da aprendizagem e a prática educacional em si ${ }^{4}$. Um novo fôlego foi dado quando Robert Gagné lançou "The conditions of learning", em 1965, que relacionava diferentes formas (ou classes) de objetivos de aprendizagem aos formatos instrucionais mais adequados. Gagné desenvolveu a ideia de fases de aprendizagem e evidenciou os processos relacionados a elas e, por levar em consideração esses aspectos, alavancou as pesquisas com tecnologias instrucionais, mas notadamente na parte de design instrucional.

A avaliação passa a ser considerada um elemento chave para o desenvolvimento dos sistemas instrucionais. E, nesse sentido, a avaliação começou a ser re-pensada em função dos objetivos de aprendizagem. Diferentemente de um sistema de avaliação que comparava os pontos obtidos pelo aluno com

\footnotetext{
${ }^{4}$ Tradução livre de "He clearly described the breach between psychological research on learning and educational practice".
} 
relação a outros alunos, os sistemas instrucionais, exatamente por terem uma característica voltada para o alcance dos objetivos educacionais, não importava a comparação com outros alunos, e sim se o aluno envolvido no sistema havia conseguido atingir seus objetivos ou não (SCHROCK, 1995). Sobre essa questão, a autora declara que o desenvolvimento dessa tecnologia de avaliação começou a ser executado em 1960 e perdura até hoje. Por conta das pesquisas em desenvolvimento e, sobretudo, investimentos governamentais que se refletiam em novos laboratórios de desenvolvimento instrucional, a década de 1960 permitiu que a área fosse mais bem visualizada e os educadores, por conta do uso massivo dos audiovisuais, começavam a aceitar a ideia - ainda que de maneira tímida, de que a instrução poderia ser desenvolvida fora do espaço geográfico das escolas. É importante salientar que, em nenhum momento, se mencionava a ausência do professor, e sim o desenvolvimento do processo educativo fora da sala de aula.

\section{O LUGAR DO AUDIOVISUAL}

A produção de audiovisuais para instrução já havia recebido um grande impulso com a criação do Division of Audio-Visual Instructional Services, mas, diante de um cenário de tantas transformações, em 1960 o nome da divisão foi alterado e passou a ser escrito sem hífen. Além disso, passou a ser chamado de Departamento de Instrução Audiovisual (DAVI) (do original: Departament of Audio Visual Instruction). Mas a simples mudança de nome não bastou para apaziguar as tensões internas que já se desenhavam. Sobre esse aspecto, Schrock (1995) relata que James Finn, Arthur Lumsdaine e outros dirigentes do (DAVI) passaram a defender a necessidade de que o campo do audiovisual passasse a se ocupar mais do planejamento e design das mensagens instrucionais, do que do produto audiovisual em si, revelando uma tensão que, até hoje, permanece bastante nítida entre os profissionais de mídia e os desenvolvedores de sistemas. A década de 1960 foi finalizada com um forte movimento para que o nome do Departamento fosse alterado para dar conta de todas as suas especificidades. Ao final, em setembro de 1969, o DAVI tornou-se o que hoje conhecemos como Association for Educational Communications and Technology (AECT).

É importante destacar que o desenvolvimento dos meios de comunicação de massas na década de 1960 foi decisivo para colocar, no centro das propostas, 
tanto o rádio quanto a televisão como mídias utilizadas pedagogicamente. Se a década anterior foi marcada pelo respaldo da Psicologia, a década de 1960 será lembrada pelo auxílio oriundo dos estudos de Comunicação. Essa tendência se consolidou na década de 1970, que assistiu ao desenvolvimento da informática que, por sua vez, reconfigurou o sentido da tecnologia educacional, dessa vez para o que foi chamado de ensino assistido por computador (EAC). Os recursos da informática eram utilizados para o ensino, mas resgatavam a ideia do ensino programado da década de 1940-1950 (PONS, 2001). Esse cenário mudou nas décadas seguintes, quando as mídias ${ }^{5}$ foram se configurando não apenas como meios de comunicação, mas também como meios para a aprendizagem.

Quando a tecnologia educacional passa a ser compreendida numa amplitude maior e, sobretudo, como forma de potencializar a comunicação com vistas ao processo educativo, pode-se falar em recursos midiáticos voltados para a educação. Não se compreende mais a tecnologia como algo mecânico, repetitivo, condicionador, mas sim como algo que, ao implicar o uso dos meios de comunicação, o faça de forma dialógica, aberta e participativa. Contemporaneamente, principalmente em função do uso intensivo dos meios de comunicação, a terminologia "mídia educativa" tem sido utilizada para designar as mesmas tecnologias educacionais, porém com uma proposta que resgata a ideia do diálogo educativo. Buscando esclarecer os termos, Pfromm Netto (2011) declara que o termo "tecnologia educacional" é mais abrangente e, em sua definição, já contempla uma dimensão que se refere às mídias utilizadas com fins pedagógicos. Portanto, enquanto tecnologia educacional, as mídias têm recebido cada vez mais atenção dos estudiosos oriundos das mais diversas áreas.

No início do século XX, pouco tempo após a invenção do cinema, os filmes cinematográficos começaram a ser utilizados pedagogicamente nas escolas. A

5 É primordial compreender que, em muitos outros países, a adoção de recursos midiáticos utilizados para fins educacionais foi chamada inicialmente de tecnologia educacional. Dadas as necessidades urgentes de alfabetização e escolarização da população, em muitos países essa tecnologia foi usada para situações de ensino a distância, o que ocasionou certo equívoco com relação aos usos dos suportes midiáticos com objetivos educacionais. A afirmação de que a tecnologia educacional é exclusivamente uma ferramenta de educação a distância é um equívoco, já visto que os vídeos (mídias audiovisuais) utilizados em sala de aula em situação presencial são também considerados tecnologias educacionais. Nesse sentido, cabe fazer a ressalva de que o giz e a lousa tradicionais são também tecnologias educacionais, uma vez que são suportes físicos modificados tecnologicamente pelo homem para servir aos objetivos pedagógicos de uma aula. 
partir desse momento, várias pesquisas começaram a ser desenvolvidas com a finalidade de verificar o potencial pedagógico dos filmes que, além de oferecerem uma nova forma de ver o mundo também possibilitavam novas formas de aprendizagem (WITTICH; SHULLER, 1979). Os recursos audiovisuais também receberam um forte impulso das pesquisas clássicas, que indicavam que os alunos conseguem reter $10 \%$ do que leem, $20 \%$ do que escutam, $30 \%$ do que veem, $50 \%$ do que veem e escutam, $70 \%$ do que se diz e discute e $90 \%$ do que se diz e em seguida se exercita (GALLEGO; ALONSO,1999, p. 28).

De acordo com Pfromm Netto (2011), a revisão crítica das pesquisas que fizeram parte do "InstructionalFilmResearchProgram" resultou em 80 pesquisas originais, compiladas por Hoban e Van Ormer (1951). Entre os resultados obtidos, destacamos alguns pontos concernentes a este artigo, quais sejam: 1 - as pessoas aprendem através dos filmes, 2 - quando utilizados de maneira apropriada, as pessoas são capazes de reter mais conteúdo por meio dos filmes e, além disso, são capazes de aprender mais em menos tempo, 3 - os filmes tendem a estimular outras formas de aprendizagem e 4 - alguns filmes são capazes de auxiliar o pensamento crítico. O relatório também determinava formas mais eficientes de uso dos filmes: "When films are used to supplement usual teaching methods, their effectiveness is more pronounced as an aid to retention than to immediate learning" (HOBAN; VAN ORMER, 1951). Embora a concepção de recursos audiovisuais seja muito mais ampla que filmes educativos, é fato que os resultados obtidos nas pesquisas contribuem muito para os estudos desses recursos na atualidade.

Babin e Kouloumdjian (1989) destacavam, na década de 1980, que o audiovisual imprimia um novo modo de compreender a realidade, por meio de imagens em movimento e sons que, por sua vez, eram capazes de representar uma nova realidade. O audiovisual estava inaugurando uma nova linguagem que se caracterizava essencialmente por comunicar ideias por meio de sensações e emoções. A escrita acabava ficando delegada a um segundo plano, já que o audiovisual era capaz de cativar mais.

Os estudos sobre narrativa audiovisual evoluíram grandemente e, aos poucos, a mídia televisiva passou a ser mais explorada do ponto de vista educacional. A vertente educativa dos estudos de televisão demonstrava bons resultados, principalmente para a aprendizagem aberta, mas carecia de investimentos e estudos aprofundados. Tais estudos, no entanto, foram relegados a um segundo plano 
com a chegada das chamadas novas tecnologias de informação e comunicação (NTIC) na década de 1980. Os primeiros projetos eram marcados pela interação do aprendiz com os computadores e motivaram uma série de discussões a respeito da influência dessas "máquinas de ensinar" tanto nas crianças como nos professores. Se, num primeiro momento, os computadores foram associados às máquinas de Skinner, pouco tempo depois já se assumia que essas máquinas poderiam proporcionar novas formas de aprendizagem. As primeiras experiências se deram com o que se convencionou chamar de informática na educação, ou seja, aquilo que diz respeito "à inserção do computador no processo de ensino-aprendizagem de conteúdos curriculares de todos os níveis e modalidades de educação"6 (VALENTE, 1999, p.1).

Com o tempo, foi possível perceber que a "utilização de computadores na educação é muito mais diversificada, interessante e desafiadora, do que simplesmente a de transmitir informação ao aprendiz" (VALENTE, 1999, p. 1), principalmente por conta dos estudos conduzidos por Papert, que resultaram na linguagem Logo, algo completamente diferente do que era feito com rubrica da "informática na educação". Com uma linguagem voltada para as crianças, o projeto de Papert propunha um novo modo de usar o computador na escola "baseado em softwares educativos que replicavam o lugar comum dos livros didáticos" (CYSNEIROS, 2007, p. 228). Para Papert, fazendo uma analogia com o lápis e o papel, o computador representava uma prótese da inteligência em desenvolvimento e poderia potencializar a construção do conhecimento à medida que estivesse sempre disponível- assim como o lápis e o papel. Os computadores são, portanto, auxiliares do processo de ensino-aprendizagem; o planejamento das atividades pedagógicas e a definição do trajeto é uma responsabilidade da Escola e do professor. A década de 1990 foi marcada pela conectividade do computador,

\footnotetext{
6 Para tornar os termos mais claros, é importante diferenciarmos "informática na educação" de "alfabetização em informática". O primeiro termo "enfatiza o fato de o professor da disciplina curricular ter conhecimento sobre os potenciais educacionais do computador e ser capaz de alternar adequadamente atividades tradicionais de ensino-aprendizagem e atividades que usam o computador" (VALENTE, 1999, p. 1-2), enquanto que o segundo, também conhecido como "computerliteracy" nos Estados Unidos busca capacitar o aprendiz para manusear o computador. No Brasil, essa linha de pensamento deu origem à inserção da disciplina "Introdução à Informática" no currículo de muitas escolas que, sem dúvida, permite ao aluno conhecer o computador, mas não altera a metodologia do ensino das disciplinas.
} 
ou seja, a máquina estava conectada à rede, e as propostas de uso desse potencial para a educação proliferaram no mundo todo.

\section{CONSIDERAÇÕES FINAIS: NOVOS RUMOS PARA O AUDIOVISUAL}

Chegamos ao século XXI com o uso intensivo e massivo dos meios de comunicação, mas com uma proposta de ensino individualizado/personalizado por meio da interatividade proporcionada pela internet. As experiências de ensino-aprendizagem podem ocorrer fora das salas de aula, nos ambientes virtuais de aprendizagem que, por sua vez, potencializam a colaboração entre os Sujeitos. Recentemente, a ideia de imersão também tem apresentado grandes possibilidades educativas e a disponibilidade de um meio de comunicação tradicionalmente conhecido (televisão) ressurge com tecnologia digital. Trata-se da TV Digital que, assim como outras mídias, também pode ser considerada uma tecnologia educacional.

Nesse contexto, os estudos envolvendo a linguagem audiovisual retornam à cena com total força. A televisão - quer seja analógica ou digital - é apenas um suporte para a veiculação desse tipo de narrativa que se faz presente não apenas em computadores pessoais, mas, sobretudo, em dispositivos móveis como tablets e smarphones. No caso do celular / smartphone, o que se verifica é que o aparelho acaba sendo uma extensão da mão humana, o que resgata o princípio mcluhaniano dos meios como extensão do homem. Pelo tamanho e princípio ergonômico, os tablets ainda implicam certas condições específicas de manuseio. Miniaturizar, no entanto, tem seus limites. Isso ocorre porque existe um limite de miniaturização em função das dimensões do corpo humano. Os suportes precisam congregar portabilidade, mobilidade e conforto para o manuseio.

Essas alterações ensejam mais que apenas a mudança dos modos de produção e distribuição, mas sim uma mudança estrutural, mental e até psíquica. Assim como ocorreu em outros momentos de rupturas paradigmáticas, esse novo período também enseja ambiguidades, inseguranças e novos desafios. A atenção que os audiovisuais têm recebido nos últimos anos decorre do fato de que a sociedade tem-se mostrado cada vez mais povoada por imagens e sons. $\mathrm{E}$ esse movimento tem-se configurado de forma tão incisiva ao longo dos anos que tem levado autores, a exemplo de Ferrés (1994) e Sartori (2000), a afirmar que é possível que, nos próximos anos, enormes contingentes populacionais passem 
da cultura da palavra (oralidade) para a cultura da imagem, sem ter atravessado a etapa intermediária representada pelo livro e a escrita. Para ele, a imagem se constitui hoje em uma forma superior de comunicação.

Nesse cenário, os audiovisuais apresentam-se cada vez mais interativos, oferecendo múltiplas possibilidades de leitura. O contexto de produção e recepção também sofre alterações, de forma que, para as novas gerações, o que antes poderia ser configurado como um ruído no processo de comunicação agora faz parte da leitura do material como um todo. Inicialmente, acreditava-se que a qualidade técnica fosse responsável por transmitir a ideia de algo claro, transparente, próximo e, com isso, pudesse aproximar conteúdo e Sujeito. O que se verifica, após diversos investimentos em televisores de tela plana, LCD, plasma, digital, 3D, interativos, entre outros adjetivos e características, é que vídeos caseiros conseguem aproximar muito mais as pessoas do que fantásticas produções e efeitos visuais. Consideradas as proporções, obviamente, os estudos conduzidos por Santos (2013) revelam que, embora muita importância seja dada para a qualidade da imagem e do som de uma produção audiovisual de uma maneira geral, é a história que realmente se sobressai. Isso explica, por exemplo, porque os campeões de acesso e visualizações no Youtube, por exemplo, não são necessariamente as melhores produções do ponto de vista da qualidade da imagem e do som. Não raro, não possuem qualidade técnica, visto que muitas sequer chegam a ser produzidas no sentido estrito da palavra, sendo apenas gravadas e compartilhadas. Ainda assim, são as mais visualizadas, compartilhadas e, inclusive, traduzidas para outras línguas.

Importante observar que, mesmo diante da proliferação de dispositivos móveis e do crescimento do índice de conectividade no mundo (GHEMAWAT; ALTMAN, 2014), o que se observa, diferentemente do que possa parecer, é que não se vê menos TV - entendida aqui como expressão dos audiovisuais-, "os conteúdos televisivos é que se expandem por múltiplas plataformas" (LOPES et al., 2011, p. 143). Isso significa que, em essência, os conteúdos audiovisuais acabam circulando em diferentes plataformas e suportes que não apenas o tradicional televisor. Ao mesmo tempo, altera-se também o esquema de recepção: o Sujeito não está mais refém das grades fixas ditadas pelas grandes emissoras. O Youtube e outras plataformas têm permitido que o sujeito vá em busca de conteúdos que correspondam a sua preferência nos momentos que escolher e entender mais 
apropriados. Observa-se ainda o crescimento e incentivo das narrativas transmidiáticas que, diferente de reproduzirem o mesmo conteúdo em diferentes plataformas, objetivam oferecer conteúdos complementares (JENKINS, 2009; SCOLARI, 2013). Também aqui o audiovisual se impõe como parte importante da narrativa transmidiática, em ambientes múltiplos com linguagens híbridas? ${ }^{7}$.

A linguagem audiovisual convoca diferentes posturas perceptivas do Sujeito aprendiz, desde a imaginação até a reinvenção da afetividade. O audiovisual é uma linguagem realmente encantadora. A pesquisa conduzida por Santos (2013) demonstrou que Sujeitos aprendizes que sentem dificuldade em demonstrar emoção, sentimentos em geral, podem acabar se revelando extremamente sensíveis (e críticos) por meio da linguagem audiovisual. A língua escrita não é a única possibilidade; ela é apenas uma delas (e talvez a mais limitada delas). Cabe ao professor estimular esses movimentos e expandir a compreensão de que todo e qualquer audiovisual pode ser educativo (FRANCO, 1997), dependendo do uso que se faça dele e das estratégias pedagógicas traçadas pelo professor. O uso da tecnologia educacional só será expressão da atividade humana (KLINGE, 2000) se nos apropriarmos dela em função de nossas necessidades.

\section{REFERÊNCIAS}

BABIN, P.; KOULOUMDJIAN, M. F. Os novos modos de aprender: a geração do audiovisual e do computador. São Paulo: Edições Paulinas, 1989.

CYSNEIROS, P. G. Resemja: PAPERT, Seymour. A máquina das crianças: repensando a escola na era da informática. Revista da FACED, Salvador, n. 12, p. 227-31, jul./dez. 2007.

FEENBERG, Andrew. Questioning technology. 3. ed. London: Routeledge, 2001.

FERRÉS, J. Video y educación. Barcelona, Espanha: Ediciones Paidós, 1994.

FRANCO, M. Linguagens audiovisuais e cidadania. Comunicação \& Educação, São Paulo, n. 9, p. 32-35, maio/ago. 1997.

GAGNÉ, R. M. The conditions of learning. New York: Holt, Rinehart, \& Winston, 1965.

\footnotetext{
${ }^{7}$ Enquanto instituição promotora do processo de ensino e aprendizagem, a escola deve contribuir para a formação e capacitação dos discentes para este novo cenário permeado pelas novas tecnologias, notadamente digitais e audiovisuais. No plano tecnológico, tem-se a emergência de tecnologias de distribuição como os podcasts e, mais recentemente, videocasts que, por sua vez, também propiciam excelentes espaços de experimentação audiovisual.
} 
GALLEGO, D. J.; ALONSO, C. M. Multimedia en la web. Madrid: Dykinson, 1999.

GENTRY, C. G. Educational technology: a question of meaning. In: ANGLIN, G. J. (Ed.). Instructional technology: past, present, and future. 2. ed. Westport, CT: Libraries Unlimited, 1995.

GHEMAWAT, Pankaj; ALTMAN, Steven A. DHL global connectedness index 2014: analyzing global flows and their power to increase prosperity. 2014. Disponivel em: <http://www. dhl.com/content/dam/Campaigns/gci2014/downloads/dhl_gci_2014_study_low.pdf $>$. Acesso em: 2 jan. 2017.

HOBAN, C. F.; VAN ORMER, E. B. Instructional film research: 1918-1950. [S.I.]: Ayer Publishing, 1951.

JANUSZEWSKI, A.; MOLENDA, M. Educational technology: a definition with commentary. Mahwah, NJ: Lawrence Erlbaum Associates, 2008.

JENKINS, H. Cultura da convergência. São Paulo: Aleph, 2009.

JOHNSON, Steven. Cultura da interface: como o computador transforma nossa maneira de criar e comunicar. Rio de Janeiro: Jorge Zahar, 2001.

KERBAUY, M. T. M.; SANTOS, V. M. Redes sociais mediadas por computadores In: BARROS, D. M. V. et al. Educação e tecnologias: reflexão, inovação e práticas. Lisboa: [s.n.], 2011a. . Panorama de l'enseignementsupérieur. In: BARRIENTOS-PARRA, Jorge (Ed.). LesGrandsémergents, L'AubeduBrésil. 47. ed. Paris: Agir, 2011b. p. 157-67.

KLINGE, Germán Doig. El desafio de la tecnología: más allá de Ícaro y Dédalo. Lima, Peru: VE, 2000.

LOPES, M. I. V. et al. Brasil: caminhos da ficção entre velhos e novos meios. In: LOPES, M. I. V.; GÓMEZ, Guillermo Orozco (Coord.). OBITEL 2011 - qualidade na ficção televisiva e participação transmidiática de audiências. São Paulo: GloboUniversidade, 2011.

LOWENTHAL, P. R.; WILSON, B. G. Labels do matter! A critique of AECT's redefinition of the field.TechTrends. 2010. Disponível em: <http://patricklowenthal.com/publications/ LabelsDoMatter--CritiqueAECTsRedefinitionOfTheField.pdf>. Acesso em: 12 abr. 2015.

PFROMM NETTO, S. Telas que ensinam: mídia e aprendizagem do cinema às tecnologias digitais. 3. ed. Campinas, SP: Alínea, 2011.

PONS, J. P. Visões e conceitos sobre a tecnologia educacional. In: SANCHO, M. J. (Ed.). Para uma tecnologia educacional. Porto Alegre: Artmed, 2001.

REISER, R. A. Instructional technology: a history. In: GAGNE, R. M. (Ed.). Instructional technology: foundations. Hillsdale, NJ: Lawrence Erlbaum Associates, 1987. p. 11-48.

SAETTLER, P. L. A history of instructional technology. New York: McGraw-Hill, 1968. 
SANTOS, V. M. Materiais audiovisuais para a educação a distância: a contribuição dos estilos de aprendizagem. 2013. 315 f. Tese (Doutorado em Educação) - Universidade Estadual Paulista Júlio de Mesquita Filho (UNESP), Araraquara, SP, 2013.

SARTORI, Giovanni. Homo videns: televisão e pós-pensamento. Lisboa: Terramar, 2000.

SCOLARI, C. Narrativas transmedia: ccuando todos los medios cuentan. Barcelona: Deusto, 2013.

SCHROCK, K. A brief history of instructional development. In: ANGLIN, G. J. (Ed.). Instructional technology: past, present, and future. 2. ed. Westport, CT: Libraries Unlimited, 1995. p. 11-9.

SEELS, B. B.; RICHEY, R. C. Instructional technology: the definition of the field. Washington, DC: Association for Educational Communications and Technology, 1994.

SELWYN, N. Education and technology: key issues and debates. Edição para Kindle. Londres: Bloomsbury, 2011. Tradução de Giselle Martins dos Santos Ferreira. Disponível em: <https://ticpe.files.wordpress.com/2016/12/neil_selwyn_keyquestions_cap1_trad_pt_final1. pdf>. Acesso em: 1ㅇmaio 2017.

SKINNER, B. F. Ciência e comportamento humano. São Paulo: Martins Fontes, 2003.

VALENTE, J. A. O computador na sociedade do conhecimento. São Paulo: UNICAMP/NIED, 1999.

WITTICH, W. A.; SCHULLER, C. F. Instructional technology: its nature and use. 6. ed. Harper \& Row Publishers, 1979.

\section{Sobre a autora:}

Vanessa Matos dos Santos: Doutora em Educação Escolar (UNESP). Doutora em Meios e Processos Audiovisuais (USP). Mestre em Comunicação Midiática (UNESP). Docente da Pós-graduação em Tecnologias, Comunicação e Educação (PPGCE), e do curso de Jornalismo da Universidade Federal de Uberlândia. E-mail: vanmatos.santos@gmail.com

\section{Recebido em maio de 2017}

Aprovado em outubro de 2017 